\title{
The height-, weight-, and BMI-for-age of Polish school-aged children and adolescents relative to international and local growth references
}

\author{
Zbigniew Kulaga', Mieczysław Litwin ${ }^{2 *}$, Marcin Tkaczyk ${ }^{3}$ Agnieszka Różdżyńska ${ }^{4}, K^{1}$ Katarzyna Barwicka', \\ Aneta Grajda', Anna Świąder ${ }^{4}$, Beata Gurzkowska', Ewelina Napieralska', Huiqi Pan ${ }^{5}$
}

\begin{abstract}
Background: The growth of children is an indicator of health and society's wellbeing. Growth references are useful in monitoring a child's growth, which is a very important part of child care. Poland's growth references are not updated regularly. Although several growth reference ranges have been developed in Poland over recent years, sampling was restricted to urban populations of major cities. The aim of this study was to assess how well Polish children match with, or diverge from, regional charts and to compare them with international growth references.

Methods: Four Polish and two international (WHO 2007 and USCDC2000) growth references were used to calculate the height, weight and BMI z-scores in a recent, large, population-representative sample of school-aged children and adolescents in Poland. The distributions of z-scores were analysed with descriptive and inferential statistical methods.

Results: Mean height z-scores calculated with the use of the WHO 2007 and USCDC2000 references were positive and significantly different from zero over the entire age range. The mean height $z$-score was closest to zero in the Poznan reference for boys (0.05) and Warszawa reference for girls (0.01). Median weight z-scores were positive under all weight references over the entire age range with only the exception of 18-year-old girls' weight z-score calculated relative to USCDC2000. Median BMI z-scores were positive in males in early childhood, decreasing with age. In the case of girls, the median BMI z-score calculated using WHO 2007 and USCDC2000 was close to zero in early childhood, decreased in adolescents and reached minimum values at age 18 years. Median BMI z-scores calculated with the use of the Lodz reference fluctuated between 0.05 and 0.2 over the studied age range.

Conclusions: In this contemporary sample of Polish school-aged children, distributions of height, weight and BMI differed from those of children from the international growth references. These differences should be considered when using the references. There exist certain limitations to the analysis of height, weight, and BMI z-scores when Polish regional references are used.
\end{abstract}

\section{Background}

A child's growth is an indicator of health $[1,2]$ and society's wellbeing $[3,4]$. Monitoring growth to identify health- or nutrition-related problems is an important task of health care providers. In practice, growth references are used: 1) by doctors and nurses involved in the care of individual children as a part of medical assessment to evaluate the growth status of a child, and 2) as

\footnotetext{
* Correspondence: m.litwin@czd.pl
2Department of Research, The Children's Memorial Health Institute, Warsaw

* Correspondence: m.litwin@czd.pl
2Department of Research, The Children's Memorial Health Institute, Warsaw, Poland
}

(c) 2010 Kulaga et al; licensee BioMed Central Ltd. This is an Open Access article distributed under the terms of the Creative Commons Attribution License (http://creativecommons.org/licenses/by/2.0), which permits unrestricted use, distribution, and reproduction in any medium, provided the original work is properly cited.

a public health tool, to summarize and compare anthropometry among groups of children [5].

Poland does not have its own growth reference data that have been constructed with a representative national sample of children and adolescents and regularly updated, for example, in ten-year intervals. Although several growth references have been developed in Poland in recent years, sampling was restricted to the urban populations of major cities and, in the case of some of the references, sampling was not random. Due to the limited representativeness of Polish local growth 
charts, the recently updated World Health Organization (WHO) international height, weight, and BMI references for children and adolescents aged 5-19 years (WHO 2007) [6] are of interest as potentially useful for the Polish population, as are the reference values from the Centers for Disease Control and Prevention (CDC) [7] (USCDC2000). The aim of the present analysis was to assess how well Polish children match with, or diverge from, regional and international growth charts. We have addressed these questions using data from a representative sample of Polish schoolchildren (7 to 18 years of age).

\section{Methods}

The analyzed data were collected in the course of the OLAF study (PL0080) in which the reference blood pressure ranges were elaborated for Polish children and adolescents. The present analysis was limited to a crosssectional sample of school children who were examined between November 2007 and March 2009. Study participants (children and adolescents 6.5-18.5 years of age) were randomly selected using two-stage sampling. Primary units (schools) were sampled from an all-schoolsin-Poland sampling frame; sampling was stratified by urban/rural area. In the second stage, all pupils in the required age ranges within the sampled schools comprised the sampling frame. Pupils in schools were selected for the survey by stratified random sampling, the stratification variables being classes. All subjects and their parents (in the case of subjects under 18 years of age) gave their informed consent to participate in the study (subjects over 16 years of age and parents gave written consent). Approval of The Children's Memorial Health Institute Ethics Committee to conduct the study was obtained before the study commenced.

The medical history of the study participants, including past and present diseases, as well as medications used, was taken from the parents. The general health status of each subject was assessed by a physician. Height was measured in duplicate (in case of a difference between measurements exceeding $4 \mathrm{~mm}$, a third measurement was taken) using a stadiometer (SECA 214) in the standing position (with no shoes), to the nearest millimeter. Body weight was recorded in light underwear to the nearest $0.05 \mathrm{~kg}$, using a digital, medical scale (Radwag WPT 100/200). Body mass index was calculated as body weight divided by height in meters squared. The exact ages of the participants were calculated from birth and examination dates. There were 13 015 children and adolescents enrolled in the study (response rate 0.70). In our analysis we excluded height measurements from the OLAF study if the child was recorded as having a posture deficiency, genetic syndrome, cancer, or other chronic disease (230 cases). The weight measurements were missing in the OLAF study sample for 1 boy and 3 girls. Thus, 6227 boys and 6558 girls aged 6.5 to 18.5 years from the OLAF study were included in the analysis of height and 6226 boys and 6555 girls in the analysis of weight and BMI. One third (33\%) of all of the children and adolescents in the sample lived in rural areas.

Four Polish growth reference ranges were compared with those of the WHO 2007 [6] and USCDC2000 [7] growth charts. The four Polish growth charts included in the present analysis were developed for urban populations of: Warszawa [8], Poznan [9], Krakow [10], and Lodz [11]. The Polish growth charts are referred to herein by the name of the city for which they were developed. The growth references for Krakow and Lodz were constructed with the LMS method [12], which is equivalent to the BCPE method used in the construction of the WHO 2007 references, while the USCDC2000 used a process similar to the LMS method.

All six growth references under consideration were used to calculate height $\mathrm{z}$-scores. Only three weight and BMI references: WHO 2007, USCDC2000, and Lodz, were used to calculate $\mathrm{z}$-scores for the OLAF sample, as the Warszawa and Poznan weight and BMI references did not account for skewness of weight and BMI, while Krakow did not provide the L, M, S parameters for the calculation. Z-scores relative to the USCDC2000 were calculated with the SAS code downloaded from the CDC web site http://www.cdc.gov/nccdphp/dnpa/ growthcharts/resources/sas.htm. Z-scores relative to the WHO 2007 were calculated with the SAS code provided by the WHO Anthro Team. The z-score (z) for a given height, weight, and $\mathrm{BMI}$ measurement $(\mathrm{X})$ relative to the Lodz reference was calculated as: $\mathrm{z}=\left((\mathrm{X} / \mathrm{M})^{\wedge} \mathrm{L}-1\right) /$ $\mathrm{L} / \mathrm{S}$ if $\mathrm{L} \neq 0$ or $\mathrm{z}=\log (\mathrm{X} / \mathrm{M}) / \mathrm{S}$ if $\mathrm{L}=0$ [12]. Height $\mathrm{z}$ scores relative to the Krakow, Warszawa and Poznan references were calculated according to the formula: $\mathrm{z}=(\mathrm{X}$-mean $) / \mathrm{SD}$.

A child was considered stunted (low height-for-age) if the height-for-age $\mathrm{z}$-score was below -2 . The means and standard deviations of $\mathrm{z}$-scores of height and percentage of stunted children were calculated separately for each sex and for each height-for-age chart. The normality of distributions of estimated height z-scores were assessed with the Kolmogorov-Smirnov test. Differences from zero of the means of height z-scores were analyzed with Student's t-test for the whole age range ( 7 to 18 years of age) and separately for each year of age. Differences of height $\mathrm{z}$-score means between reference ranges were analyzed with the paired t-test. Differences in the distribution of stunting according to sex and reference range were tested with the McNemar test. Differences in the prevalence of stunting between genders were tested with the chi square test. Due to the skewed nature of weight 
and BMI distributions, medians and inter-quartile ranges (IQRs) are presented by sex and age. Data were processed with the MsAccess database and MsExcel spreadsheet. All analyses were conducted with SAS 9.1 for Windows.

\section{Results}

Additional file 1: Table S1 shows the height, weight, and BMI summary statistics of the OLAF study subjects included in the analysis. Due to the skewed nature of weight and BMI distributions, medians and inter-quartile ranges (IQRs) are presented.

Table 1 shows the means of height z-scores, which, calculated using the WHO 2007 and USCDC2000 height references, were positive and higher than the means calculated using Polish regional references. The confidence interval of mean height $\mathrm{z}$-scores included zero only for the Warszawa growth chart for girls. For all other studied reference ranges, statistically significant differences from zero of the mean height $\mathrm{z}$-scores $(\mathrm{p}=$ 0.0001) were demonstrated for both sexes, however, the Poznan and Warszawa mean height $\mathrm{z}$-scores were close to zero (from -0.06 to 0.08).

The mean height $\mathrm{z}$-score difference from zero was systematically positive over the whole age range (both boys and girls) (Figure 1) and statistically significant in relation to the WHO 2007 and USCDC2000 height references in each year of age (Additional file 2: Table S2).

With the exception of $\mathrm{z}$-scores calculated using the Lodz height reference, mean height $\mathrm{z}$-scores were higher in males compared with females for all other tested growth charts. The difference between genders was statistically significant ( $<$ 0.01) for the WHO 2007, USCDC2000, Warszawa, Krakow, and Poznan growth charts.

Table 1 Polish children and adolescents (the OLAF study sample) mean height $z$-scores relative to the six references and statistical testing

\begin{tabular}{|c|c|c|c|c|c|c|c|}
\hline $\begin{array}{l}\text { reference } \\
\text { boys }\end{array}$ & $\mathbf{N}$ & Mean & $95 \% \mathrm{Cl}$ & SD & $p$ & Min. & Max. \\
\hline WHO 2007 & 6227 & 0.50 & 0.470 .52 & 0.99 & $<.0001$ & -3.03 & 4.37 \\
\hline USCDC2000 & 6227 & 0.45 & 0.430 .48 & 0.97 & $<.0001$ & -2.79 & 4.02 \\
\hline Krakow & 6227 & 17 & 0.150 .20 & 1.02 & $<.0001$ & -3.37 & 3.85 \\
\hline Warszawa & 6227 & 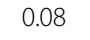 & 0.05 & 1.06 & 01 & -3.63 & 4.07 \\
\hline Poznan & 6227 & 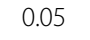 & 8 & 1.09 & 01 & 3.73 & 4.08 \\
\hline odz & 6227 & 0.14 & 0 & 1.04 & $<.0001$ & -3.66 & 3.88 \\
\hline \multicolumn{8}{|l|}{ girls } \\
\hline WHO 2007 & 6558 & . & 0.32 & 0.95 & $<.0$ & -3.47 & 4.29 \\
\hline USCDC2000 & 6558 & 0.33 & 0.310 .36 & 0.94 & $<.0001$ & -3.03 & 3.95 \\
\hline Krakow & 6558 & 0.09 & 0.070 .12 & 1.03 & $<.0001$ & -3.34 & 4.33 \\
\hline Warszawa & 6558 & 0.01 & -0.020 .03 & 1.05 & 0.6338 & -3.73 & 4.19 \\
\hline Poznan & 6558 & -0.06 & $-0.09-0.03$ & 1.11 & $<.0001$ & -3.86 & 4.57 \\
\hline Lodz & 6558 & 0.15 & 0.130 .18 & 1.03 & $<.0001$ & -3.49 & 4.43 \\
\hline
\end{tabular}

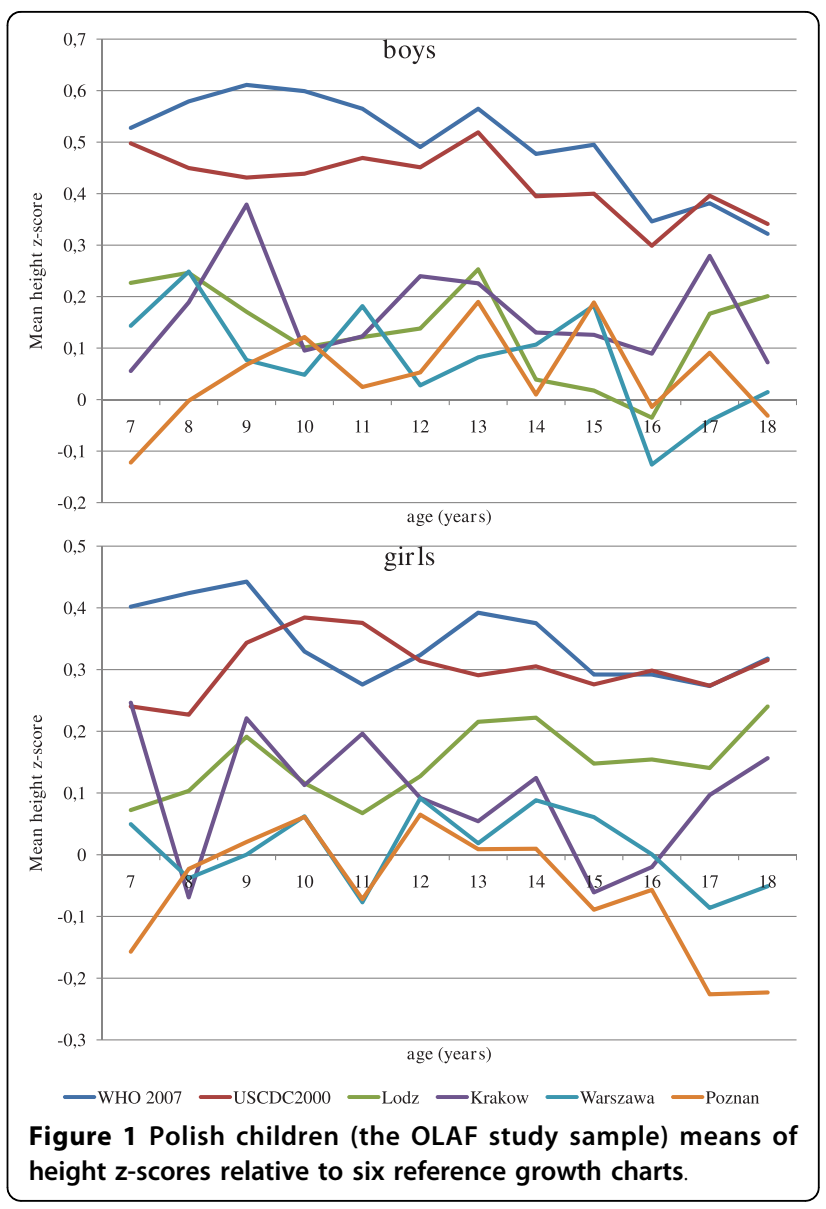

The differences between mean $\mathrm{z}$-scores for height were statistically significant $(\mathrm{p}<0.0001)$ compared with the WHO 2007 and USCDC2000 charts for each of the Polish growth references and between each pair of Polish reference growth charts.

The use of WHO 2007 and USCDC2000 height-forage references resulted in an estimated stunting (height-for-age $\mathrm{z}$-score less than-2) prevalence of below $1 \%$ among OLAF study participants. Figure 2 presents stunting rates in the OLAF study sample calculated using the six references. In general, the rate of stunting was higher in girls than in boys, with the exception of the Lodz height reference. The six references showed differences in stunting rates: the lowest were in the WHO 2007 and USCDC2000 references, and the highest in Poznan. There were significant differences $(\mathrm{p}<0.001$, McNemar tests) in the prevalence of stunting when Polish references were compared with the WHO 2007 and USCDC2000 growth charts.

The distributions of weight and BMI z-scores calculated relative to the WHO 2007 and Lodz growth references were right-skewed, whereas the distributions 


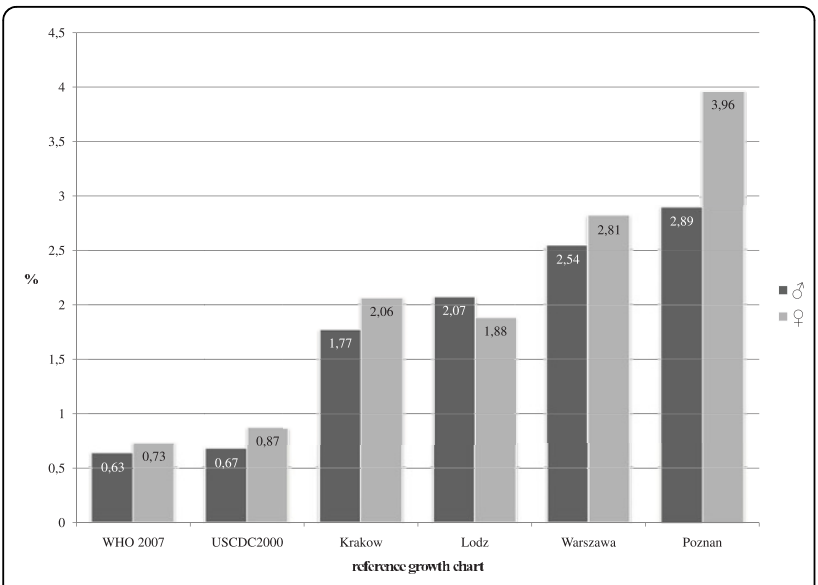

Figure 2 Prevalence of stunting among Polish school children (the OLAF study sample) using the six references. Stunting was defined as height $z$-scores $<-2$.

of the OLAF study sample weight and BMI z-scores calculated relative to the USCDC2000 growth references were close to normal with a negative skew tendency. The WHO 2007 does not provide weight reference values for children older than 10 years, thus $\mathrm{z}$-scores were calculated for ages from 7 to 10 years only. Table 2 shows descriptive statistics of weight and BMI z-score by sex calculated with the use of two international and one Polish growth reference.

Under all three weight references, over the entire age range, median weight $\mathrm{z}$-scores were positive, with only the exception of 18-year-old girls' weight $\mathrm{z}$-score relative to the USCDC2000. In both sexes, the median weight $\mathrm{z}$-score calculated using the WHO 2007 reference was higher compared with the USCDC2000 and Lodz weight references and, in contrast with the USCDC2000 and Lodz, the median weight z-scores were increasing through childhood (Table 2, Figure 3.). Median weight $\mathrm{z}$-scores, calculated using the Lodz and USCDC2000 weight references lie closer to zero in boys (0.01) and girls (0.01), respectively (Figure 3 ). Figure 3 shows the median weight $\mathrm{z}$-score calculated using three weight references plotted against age for boys and girls separately.

Median BMI z-scores were positive in males in early childhood, decreasing at later ages, and crossing into negativity at the age of 10 and 13 years in the case of z-scores calculated using the Lodz, WHO 2007, and USCDC2000 references, respectively (Figure 4). For all references, the median BMI z-score in boys reached a minimum at age 13 years and then returned to slight positivity, becoming very close to zero (from -0.02 to 0.04 USCDC2000 and WHO 2007, respectively). In the case of girls, the median BMI z-score calculated with the use of WHO 2007 and USCDC2000 was close to zero in early childhood, decreasing in adolescence and reaching minimum values at age 18 years. The median BMI z-score calculated with the use of the Lodz reference fluctuated between 0.05 and 0.2 over the age-range studied (Figure 4).

\section{Discussion}

Periodic health examinations of children and adolescents have been a part of preventive child health programmes in many countries, including Poland. At the examination, it is required to assess centiles of height, weight, and BMI for a child. Screening children's height seems to be cost-effective in detecting height-related disorders and for the detection of other undiagnosed conditions [13]. Growth charts should allow for a precise diagnosis of stunting and disturbances of weight-to-height proportion(s) (underweight and overweight) $[14,15]$. Currently, the function of growth charts with regard to disturbances of weight is of increasing importance for public health. This is due to the rapidly rising prevalence and magnitude of childhood obesity, which is linked to the incidence of metabolic syndrome [16]. Available growth references have several limitations. In 1995, the WHO Expert Committee established guidelines for preparation of the international growth standards (the sample should comprise healthy children with unconstrained growth, deriving from developed and developing countries; the sample should be characterised by: absence of secular

Table 2 Polish children and adolescents (the OLAF study sample) median weight and BMI z-scores relative to the WHO 2007, USCDC2000, and Lodz growth references

\begin{tabular}{|c|c|c|c|c|c|c|c|c|c|c|}
\hline \multirow{2}{*}{$\begin{array}{l}\text { reference } \\
\text { boys }\end{array}$} & \multicolumn{5}{|c|}{ weight z-score } & \multicolumn{5}{|c|}{ BMI z-score } \\
\hline & $\mathrm{N}$ & Min. & Median & Max. & IQR & $\mathrm{N}$ & Min. & Median & Max. & IQR \\
\hline WHO 2007 & 1837 & -3.08 & 0.52 & 5.92 & 1.72 & 6226 & -4.18 & 0.11 & 5.91 & 1.65 \\
\hline USCDC2000 & 6226 & 3.71 & 0.30 & 3.67 & 1.38 & 6226 & -5.03 & 0.06 & 2.96 & 1.51 \\
\hline Lodz & 6226 & -3.04 & 0.10 & 3.71 & 1.31 & 6226 & -3.93 & 0.03 & 3.64 & 1.34 \\
\hline \multicolumn{11}{|l|}{ girls } \\
\hline WHO 2007 & 1778 & -3.17 & 0.29 & 5.06 & 1.57 & 6555 & -3.90 & -0.07 & 4.54 & 1.41 \\
\hline USCDC2000 & 6555 & -4.36 & 0.10 & 3.27 & 1.26 & 6555 & -4.39 & -0.06 & 2.73 & 1.32 \\
\hline Lodz & 6555 & -4.40 & 0.18 & 3.94 & 1.33 & 6555 & -4.24 & 0.14 & 3.62 & 1.30 \\
\hline
\end{tabular}



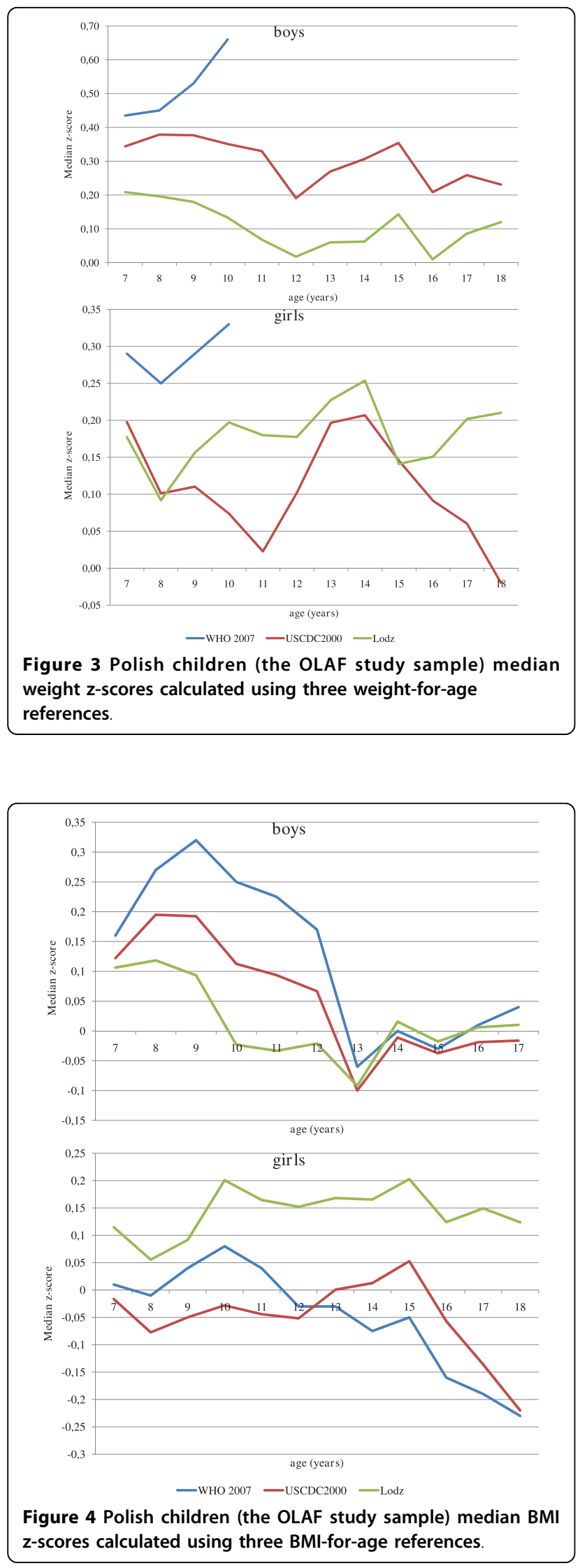

trends, sufficient size, determined cut-off with adequate specificity and sensitivity) [17]. Both the WHO 2007 and USCDC2000 growth references were based mainly on cross-sectional samples with sparse longitudinal data. The influence of a secular trends could not be ruled out.

Our findings demonstrate differences between Polish regional growth charts and the charts based on samples from the USA. The WHO 2007 reference for children aged 5-19 years is based on the 1977 National Center for Health Statistics NCHS/WHO data set, which is used in part in the USCDC2000 reference, but the CDC reference includes some more recent data sets as well. For this reason, the mean z-scores shown in Figure 1 are similar for the WHO 2007 and USCDC2000, with the USCDC2000 score being slightly lower. The comparison shows that mean height $\mathrm{z}$-scores calculated with the WHO 2007 and USCDC2000 height references significantly diverged from zero (means and confidence intervals), whereas mean height $\mathrm{z}$-scores calculated using local Polish growth references, matched zero better. Clinically and statistically important differences between the height of the sampled Polish children and of the US reference population should impose caution when interpreting Polish children's blood pressure using the Fourth Task Force report tables [18] constructed for age and height centiles. Estimation of the height centiles of Polish children using Polish growth references will provide substantially different results than if the WHO 2007 or USCDC2000 growth references are used. As a consequence of this, the cut-off for high blood pressure would differ for a given height.

The observed differences may be attributed to both socioeconomic and genetic factors $[19,20]$. The analysis performed by Haas et al. clearly showed that pre-pubertal children of most populations grew similarly, but significant differences were revealed in the pubertal stages, in which the European population diverged from the WHO standard by revealing higher values [20]. Surprisingly, our results showed a partially opposite tendency, with lower mean z-scores in pubertal (0.3) than in younger male subjects $(0.5)$. The cross-sectional design of the OLAF study and the influence of improving economic status in Poland (over the last few years) could be an explanation for this observation.

Experts agree that children and adolescents grow similarly when exposed to similar external conditions of growth. The influence of genetic factors might be postulated to some degree as well [17].

Secular trends, body composition, and sexual maturation are critical determinants in the interpretation of anthropometric measures. These constitute the main obstacles in the development of both local and universal growth charts. The OLAF study was designed closer to WHO guidelines to be more applicable for the Polish 
population. Some of the shortcomings mentioned above cannot be ruled out, however. The data from the Czech Republic reported by Vignerova showed that countrywide growth charts should be updated every 10 years with no significant changes in Body Mass Index or weight-for-height normal values [21]. This strategy may prevent inadequate assessment of overweight and obesity. Moreover, the authors reported that the secular trend in the Czech Republic stopped (except for adolescents). Presumably, this observation might be extrapolated to Poland (a neighbouring country). These findings are not surprising, but of essential clinical relevance. Application of universal growth references or the growth reference of another country to a specific population can lead to underestimation or overestimation of the real rate of growth retardation [22,23]. Additionally, it may negatively influence early detection of other measures related to height-for-age [24].

It is noteworthy that the use of local references constructed with mean and SD only, without accounting for weight and BMI skewness, will give misleading results. For example, the calculation of BMI z-scores using the Warszawa (the most popular in Poland), Poznan and Krakow references resulted in several values greater than six (data not presented in this paper), which are considered implausible by others [25].

In girls from the contemporary sample of Polish children and adolescents, median BMI z-scores calculated using international BMI-for-age references, were closer to zero than with the Lodz standard. In boys, all three compared BMI standards revealed an interesting pattern of median BMI z-score changes from childhood into adolescence. In the age range from 7 to 9 years, median z-scores were positive (more so in the case of the international reference compared with the Polish reference), decreasing into adolescence (age from 13 to 18 years). Much the same pattern of BMI change from childhood to adolescence has recently been reported for three historical British national birth cohorts [26]. The contemporary sample of Polish boys differs in terms of BMI distribution from the Lodz growth reference in the age group 7-9 years and from the WHO 2007 and USCDC2000 in the age group 7-12 years. The difference may be explained by an earlier BMI rebound in the reference data and by increasing obesity among young children in Poland. Similar findings were reported for Chinese boys [27].

\section{Conclusions}

In this contemporary sample of Polish school-aged children and adolescents, distributions of height, weight and BMI differed from those of children in the international growth references. These differences should be taken into consideration when the references are applied. The analysis of height, weight, and BMI z-scores using Polish regional references has certain limitations. Determining the validity and applicability of an existing growth reference and developing a reference based on a national representative sample are important public health functions.

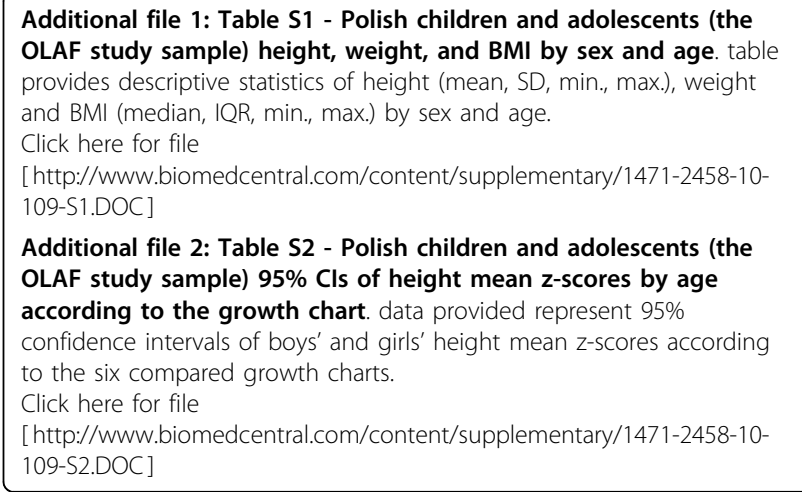

\section{Abbreviations}

BMI: body mass index; BCPE: The Box-Cox power exponential; CDC: Centers for Disease Control and Prevention; Cl: confidence interval; IQR: inter-quartile range; max.: maximum; min.: minimum; NCHS: National Center for Health Statistics; SD: standard deviation; WHO: World Health Organization;

\section{Acknowledgements}

This publication used the OLAF study data. The OLAF study was supported by the European Economic Area Financial Mechanism, the Norwegian Financial Mechanism, and the Ministry of Science and Higher Education of Poland; grant number: PL0080. The following investigators participated in the OLAF study team and conducted study procedures in the regions: Białystok: Agnieszka Rybi-Szumińska, Michał Szumiński, Katarzyna TarantaJanusz, Edyta Tenderenda, Anna Wasilewska; Bydgoszcz: Beata Jasińska; Gdańsk: Piotr Czarniak, Dominik Świêtoń, Przemysław Szcześniak; Kraków: Monika Miklaszewska, Anna Moczulska, Katarzyna Wilkosz, Katarzyna Zachwieja, Iwona Ogarek; Lublin: Marek Majewski, Aleksandra Sobieszczańska-Droździel, Izabela Szlązak, Paweł Szlązak, Małgorzata Zajączkowska; Łódź: Anna Półtorak-Krawczyk, Monika Pawlak-Bratkowska; Opole: Danuta Gmyrek; Poznań: Tomasz Krynicki, Jolanta Sołtysiak; Toruń: Roman Stankiewicz, Sława Zbucka; Warszawa: Robert Pietruczuk, Jan Szpor; Wrocław: Jacek Kleszczyński, Magdalena Naleśniak, Anna Wawro, Irena Wikiera-Magott, Danuta Zwolińska; Zabrze: Piotr Adamczyk, Tatiana Augustyn-Iwachów, Beata Banaszak, Omar Bjanid, Katarzyna Broll-Waśka, Aurelia Morawiec-Knysak.

Special thanks to the WHO Anthro Team for providing SAS code for the height, weight and BMI z-scores calculations.

\section{Author details}

'Public Health Division, The Children's Memorial Health Institute, Warsaw, Poland. '2Department of Research, The Children's Memorial Health Institute, Warsaw, Poland. ${ }^{3}$ Department of Nephrology and Dialysis, Polish Mother's Memorial Hospital Research Institute, Łódź, Poland. ${ }^{4}$ Anthropology Division, Department of Paediatrics, The Children's Memorial Health Institute, Warsaw, Poland. ${ }^{5} \mathrm{MRC}$ Centre of Epidemiology for Child Health, UCL Institute of Child Health, UK.

\section{Authors' contributions}

ZK conceived the study, conducted field examinations, did statistical analyses, and drafted the manuscript. ML conceived the study and drafted the manuscript. MT conducted field examinations and drafted the manuscript. AR conceived the study, conducted field examinations and drafted the manuscript. KB conceived the study, conducted field 
examinations and did statistical analyses. AG conducted field examinations, did statistical analyses. AS conducted field examinations and drafted the manuscript. BG collected, assembled and processed data, and did statistical analyses. EN collected, assembled and processed data. HP conceived the study, did statistical analyses and drafted the manuscript. All authors contributed to the drafting and revisions of the manuscript. All authors read and approved the revised manuscript.

\section{Competing interests}

The authors declare that they have no competing interests.

Received: 7 August 2009

Accepted: 4 March 2010 Published: 4 March 2010

\section{References}

1. Report of a WHO Expert Committee: Physical status: the use and interpretation of anthropometry. Geneva 1995

2. Gelander L: Children's growth: a health indicator and a diagnostic tool. Acta Paediatr 2006, 95:517-518.

3. Tanner JM: Growth as a mirror of the condition of society: secular trend and class distinction. Acta Paediatr Jpn 1987, 29:96-102.

4. Komlos J: Preface. Stature, Living Standards, and Economic Development Essays in Anthropometric History Chicago: The University of Chicago PressKomlos J 1994, 9-11.

5. Cole TJ: Growth references and standards. Human Growth and Development San Diego: Academic PressCameron N 2006, 386.

6. de Onis M, Onyango AW, Borghi E, Siyam A, Nishida C, Siekmann J: Development of a WHO growth reference for school-aged children and adolescents. Bull World Health Organ 2007, 85:660-667.

7. Kuczmarski RJ, Ogden CL, Guo SS, Grummer-Strawn LM, Flegal KM, Mei Z, Wei R, Curtin LR, Roche AF, Johnson CL: 2000 CDC growth charts for the United States: methods and development. Vital Health Stat 2002, 11:1-190.

8. Palczewska I, Niedzwiedzka Z: Somatic development indices in children and youth of Warsaw. Med Wieku Rozwoj 2001, 5(Suppl 1):18-118.

9. Krawczyński M, Krzyżaniak A, Walkowiak J: Developmental standards of body height and weight in children and adolescents between 3-18 years of age in the city of Poznań. Pediatria Praktyczna 2000, 8:341-353.

10. Gołąb S, Chrzanowska M: The child of Cracow 2000. The level of the biological development in Cracow children and youth. Kraków: Academy of Physical Education in Cracow 2002.

11. Rosset I, Roślak M, Grabowska J, Borowska-Strugińska B, Lorkiewicz W, Sitek A, Stolarczyk H, Śmiszkiewicz-Skwarska A, Żądzińska E: The state of physical development of children in Łódź. Dziecko łódzkie 2004. Normy rozwoju biologicznego Łódź: Medical University in ŁódźŻądzińska E 2009, 65-100.

12. Cole TJ, Green PJ: Smoothing reference centile curves: the LMS method and penalized likelihood. Stat Med 1992, 11:1305-1319.

13. Fayter D, Nixon J, Hartley S, Rithalia A, Butler G, Rudolf M, Glasziou P, Bland M, Stirk L, Westwood M: Effectiveness and cost-effectiveness of height-screening programmes during the primary school years: a systematic review. Arch Dis Child 2008, 93:278-284.

14. Hulse JA, Schilg S: Monitoring children's growth. Relation between height and weight centiles may be more useful. BMJ 1996, 312:122.

15. Cole TJ: A chart to link child centiles of body mass index, weight and height. Eur J Clin Nutr 2002, 56:1194-1199.

16. Steinberger J, Daniels SR, Eckel RH, Hayman L, Lustig RH, McCrindle B, Mietus-Snyder ML: Progress and challenges in metabolic syndrome in children and adolescents: a scientific statement from the American Heart Association Atherosclerosis, Hypertension, and Obesity in the Young Committee of the Council on Cardiovascular Disease in the Young; Council on Cardiovascular Nursing; and Council on Nutrition, Physical Activity, and Metabolism. Circulation 2009, 119:628-647.

17. Butte NF, Garza C, de Onis M: Evaluation of the feasibility of international growth standards for school-aged children and adolescents. J Nutr 2007, 137:153-157.

18. National High Blood Pressure Education Program Working Group on High Blood Pressure in Children and Adolescents: The fourth report on the diagnosis, evaluation, and treatment of high blood pressure in children and adolescents. Pediatrics 2004, 114:555-576.
19. Wang Y, Moreno LA, Caballero B, Cole TJ: Limitations of the current World Health Organization growth references for children and adolescents. Food Nutr Bull 2006, 27(Suppl 4):S175-S188.

20. Haas JD, Campirano F: Interpopulation variation in height among children 7 to 18 years of age. Food Nutr Bull 2006, 27(Suppl 4):S212-S223.

21. Vignerova J, Lhotska L: A fresh look at growth assessment of infants and young children in the Czech Republic in context of international developments. Cent Eur J Publ Health 2006, 14:97-100.

22. van Buuren S, van Wouwe JP: WHO Child Growth Standards in action. Arch Dis Child 2008, 93:549-551.

23. Hui LL, Schooling CM, Cowling BJ, Leung SS, Lam TH, Leung GM: Are universal standards for optimal infant growth appropriate? Evidence from a Hong Kong Chinese birth cohort. Arch Dis Child 2008, 93:561-565.

24. Wright C, Lakshman R, Emmett P, Ong KK: Implications of adopting the WHO 2006 Child Growth Standard in the UK: two prospective cohort studies. Arch Dis Child 2008, 93:566-569.

25. Tate AR, Dezateux C, Cole TJ: Is infant growth changing?. Int J Obes 2006, 30:1094-1096

26. Silverwood RJ, Leon DA, De Stavola BL: Long term trends in BMI: are contemporary childhood BMI growth references appropriate when looking at historical datasets?. LLCS 2009, 1:27-44.

27. Pan $H$, Jiang $Y$, Jing $X, F u S$, Jiang $Y$, Lin $Z$, Sheng $Z$, Cole TJ: Child body mass index in four cities of East China compared to Western references. Ann Hum Biol 2009, 36:98-109.

\section{Pre-publication history}

The pre-publication history for this paper can be accessed here:http://www. biomedcentral.com/1471-2458/10/109/prepub

doi:10.1186/1471-2458-10-109

Cite this article as: Kulaga et al:: The height-, weight-, and BMI-for-age of Polish school-aged children and adolescents relative to international and local growth references. BMC Public Health 2010 10:109.

\section{Submit your next manuscript to BioMed Central and take full advantage of:}

- Convenient online submission

- Thorough peer review

- No space constraints or color figure charges

- Immediate publication on acceptance

- Inclusion in PubMed, CAS, Scopus and Google Scholar

- Research which is freely available for redistribution

Submit your manuscript at www.biomedcentral.com/submit
C Biomed Central 